\title{
Fluid intake and industrial processing in apple juice induced chronic non-specific diarrhoea
}

\author{
J H Hoekstra, J H L van den Aker, Y F Ghoos, R Hartemink, C M F Kneepkens
}

\begin{abstract}
Dietary factors have been shown to contribute to the occurrence or persistence of chronic non-specific diarrhoea (CNSD). Among these are low dietary fat, high fluid consumption, and the consumption of apple juice. Prompted by the clinical impression that freshly pressed and unprocessed ('cloudy') apple juice was less likely to induce diarrhoea than normal, enzymatically processed ('clear') apple juice, both juices were compared in terms of carbohydrate malabsorption, gastric emptying, and effects on defecation patterns. Clear and cloudy apple juice differ in their fibre and non-absorbable monosaccharide and oligosaccharide contents. Ten healthy children aged 3.6 to 5.9 years ingested $10 \mathrm{ml} / \mathrm{kg}$ of clear and cloudy apple juice; in five of them it was enriched with $40 \mathrm{mg}$ of $\left[1-{ }^{13} \mathrm{C}\right]$-glycine. Clear apple juice resulted in increased ( $\geqslant 20$ ppm) breath hydrogen excretion in $8 / 10$, compared with $5 / 10$ after cloudy apple juice; peak breath hydrogen was higher in the clear apple juice group (35 (4) and 18 (3) ppm, respectively). Gastric emptying as determined by means of labelled breath carbon dioxide $\left({ }^{13} \mathrm{CO}_{2}\right)$ excretion was similar with both juices. In a four week crossover clinical trial 12 children, formerly diagnosed as having CNSD, were given extra clear fluids (excluding fruit juices; $\geqslant 50 \%$ over basal consumption), clear apple juice, or cloudy apple juice, for five day periods. Extra fluids and cloudy apple juice did not influence stool frequency and consistency compared with the basal period. In contrast, clear apple juice significantly promoted diarrhoea. It is suggested that, in addition to fructose, the increased availability of non-absorbable monosaccharides and oligosaccharides as a result of the enzymatic processing of apple pulp is an important aetiological factor in apple juice induced CNSD.
\end{abstract}

(Arch Dis Child 1995; 73: 126-130)

Keywords: chronic diarrhoea, fluid intake, stable isotopes, breath tests.

Apple juice is a popular drink in young children. It has been shown repeatedly that a high consumption of apple juice is related to the aetiology and perpetuation of symptoms in children with chronic non-specific diarrhoea (CNSD; toddler's diarrhoea). ${ }^{1-3}$ In a previous study we showed that, contrary to fructose, sorbitol malabsorption does not contribute significantly to apple juice malabsorption. ${ }^{4}$ Moreover, besides fructose other factors in apple juice, possibly complex carbohydrates originating from the fruit skin, seem to be capable of provoking breath hydrogen production and therefore CNSD symptoms $(\mathrm{J} \mathrm{H}$ Hoekstra, J H L van den Aker, R Hartemink, C M F Kneepkens. Fruit juice malabsorption: not only fructose. Acta Paediatr 1995). When considering the role of apple juice in CNSD, however, fluid consumption itself has to be taken into account, as it has been shown before that in young children excessive fluid intake, irrespective of its composition, could maintain chronic diarrhoea. ${ }^{5}$

To our knowledge only one prospective study has ever been done focusing on dietary factors associated with CNSD. Cohen et al, in 1979 , showed that increasing the percentage of dietary energy derived from fat significantly improved defecation characteristics in children with CNSD; no mention was made of the consequences of dietary manipulation for intakes and sources of fluids and carbohydrates. ${ }^{6}$ The present prospective study was prompted by our clinical impression that 'cloudy', that is, freshly pressed and unprocessed, apple juices were less likely to induce diarrhoea than the more usual enzymatically processed clear juices. As excessive use of apple juice would influence fluid consumption, which itself could induce diarrhoea, we also investigated the effects of increasing water consumption on defecation. This clinical study was preceded by a study of breath hydrogen excretion and gastric emptying as influenced by differently processed apple juice, in order to exclude the possibility that the observed differences could be simply explained by fibre induced alteration of gastric emptying rate.

\section{Subjects and methods}

BREATH TESTS

Ten healthy children (eight boys), ages 3.6 to 5.9 years (mean age 4.5 years) participated in this study. The night before the test they were allowed a rice based standard meal in order to obtain low breath hydrogen and labelled carbon dioxide $\left({ }^{13} \mathrm{CO}_{2}\right)$ concentrations. All children were tested with $10 \mathrm{ml} / \mathrm{kg}$ body weight, with a maximum of $250 \mathrm{ml}$, of clear unsweetened apple juice (Goudappeltje, Riedel, Ede, The Netherlands), and on a separate day with the same amount of cloudy apple juice (Löffler Natuurtoebele Appelsap, Natufood, Harderwijk, The Netherlands). The digestible carbohydrate contents and osmolalities of both juices were fully comparable. We 
tested two samples each and found no significant differences. In clear apple juice fructose, glucose, and sorbitol were present in amounts of 64 and $68 \mathrm{~g} / \mathrm{l}, 24$ and $26 \mathrm{~g} / \mathrm{l}$, and $3 \cdot 1$ and $3 \cdot 8$ $\mathrm{g} / \mathrm{l}$, respectively; in cloudy apple juice, in amounts of 65 and $68 \mathrm{~g} / \mathrm{l}, 25$ and $27 \mathrm{~g} / \mathrm{l}$, and 3.3 and $3.9 \mathrm{~g} / \mathrm{l}$, respectively. Osmolality as determined with freezing point depression was $700 \mathrm{mmol} / \mathrm{kg}$ for clear apple juice and 770 $\mathrm{mmol} / \mathrm{kg}$ for cloudy apple juice; in both juices, $\mathrm{pH}$ ranged between $3 \cdot 3$ and $3 \cdot 4$.

In $5 / 10$ children, gastric emptying was investigated simultaneously using a previously described technique. ${ }^{7}$ Because of the necessity of a prolonged period of resting and of full cooperation with breath sampling, only the older children could participate in this part of the study. A dose of $40 \mathrm{mg}$ of $\left[1-{ }^{13} \mathrm{C}\right]$-glycine (99\% enrichment; Isotec Inc, Miamisburg, Ohio, USA) was suspended in the juices just before ingestion.

The substrates were administered in a random order with an interval of at least three days between tests. Breath samples were taken five minutes before ingestion and subsequently every 15 minutes for 2.5 hours. In order to provide a constant basal carbon dioxide production, the children were kept rested during the test. All samples were collected in duplicate by standard techniques. ${ }^{89}$ Hydrogen was analysed immediately with the Lactoscreen breath tester (Hoek Loos, Rotterdam, The Netherlands). A peak breath hydrogen increase of $\geqslant 20 \mathrm{ppm}$ over basal level was considered indicative of carbohydrate malabsorption. The ${ }^{13} \mathrm{C} /{ }^{12} \mathrm{C}$ ratio in exhaled breath was measured by isotope ratio mass spectrometry (ABCA, Europa Scientific, Crewe, UK) and expressed as $\delta$ value. All $\delta$ values are given versus the classic reference standard for ${ }^{13} \mathrm{C}$ enrichment, PDB (Pee Dee Belemnitella). Assuming a total carbon dioxide production of $300 \mathrm{mmol} / \mathrm{m}^{2}$ body surface area/hour, the amount of ${ }^{13} \mathrm{C}$ recovered in breath was calculated as a percentage of the dose administered. 9 Body surface area was estimated by the formula of Haycock et al. ${ }^{10}$ The results were used to calculate gastric half emptying time and gastric emptying coefficient. $^{7}$

\section{CLINICAL TRIAL}

Toddlers with a previous diagnosis of CNSD, according to the criteria of Davidson and Wasserman, ${ }^{11}$ were sought for this study. They were referred by their family physician to one of us $(\mathrm{JHH})$. All had watery diarrhoea (3-6 times daily) for at least three weeks. Dietary history revealed high (more than $400 \mathrm{ml} /$ day) apple juice consumption in all. Other relevant causes of chronic diarrhoea, such as infectious diarrhoea, lactose intolerance, and coeliac disease were excluded. All children had a good clinical response with a decline of symptoms after a normal diet free of apple juice was re-established. Three to six months after normalisation of defecation patterns, the parents of 18 children were asked to participate in the study. After having received oral and written information, 12 of them agreed. Financial compensation was offered to cover extra expenses (for example, for nappies).

There were nine boys and three girls with a mean age of $2 \cdot 2$ years (range $1 \cdot 4-3.3$ years); all completed the study. Their weights were between 10th and 90th centiles for height. Judged by their parents all children were in a good state of health and had optimal stool consistency. At the beginning of the trial and at weekly intervals thereafter one of us (JHLA) made home visits in order to give appropriate instructions, to supply the two types of apple juice, and to collect the data sheets. Measuring cups were provided and the parents were asked to record all clear fluids offered in between meals, as well as leftovers, with an accuracy of $+/-10 \mathrm{ml}$. Throughout the study, the consistency of each stool specimen was graded subjectively and classified into one of four levels of consistency: (0) normal: the stools are formed (maintain their shape) or semiformed, partly soft; (1) soft: the stools are unformed, will not pour, jelly-like; (2) semiliquid: the stools pour, have the consistency of milkshake, honey, or ketchup; (3) runny: the stools pour more easily, are watery. For each period, a five day diarrhoea score was calculated by adding the consistency scores of all stools passed in a study period.

In the baseline period the parents recorded the amounts of clear fluids the children consumed in between meals; dairy products and other meal related fluid intakes were neglected. Immediately after the basal period the children were randomised. Two days later they started with one of three interventions, each lasting five days. Between two interventions a two day rest period was instituted, with the children returning to their normal (prestudy) fluid consumption. The interventions consisted of the controlled intake of extra clear fluids (including lemonades, tea, water; excluding fruit juices), exclusively cloudy apple juice, or exclusively clear apple juice, respectively. The six possible intervention orders were assigned balanced over the 12 children.

In the extra clear fluids period the parents were instructed to offer clear fluids, but no apple juice, to the children in amounts at least $50 \%$ over the fluid intake levels recorded in the baseline periods. In the two apple juice intervention periods, clear or cloudy apple juice, respectively, fully replaced the clear fluids given normally; the children were, however, not stimulated to increase their intakes (but could do so on their own initiatives). The parents were instructed not to change other components of the diet, including meals and diary products, during any of the intervention periods.

Approval for these studies was given by the local ethics committee. Informed written consent was obtained from the parents.

\section{STATISTICS}

All results are given as mean (SEM). For the breath tests significance of differences between mean values was determined using Student's $t$ test for paired data (two sided), and between 


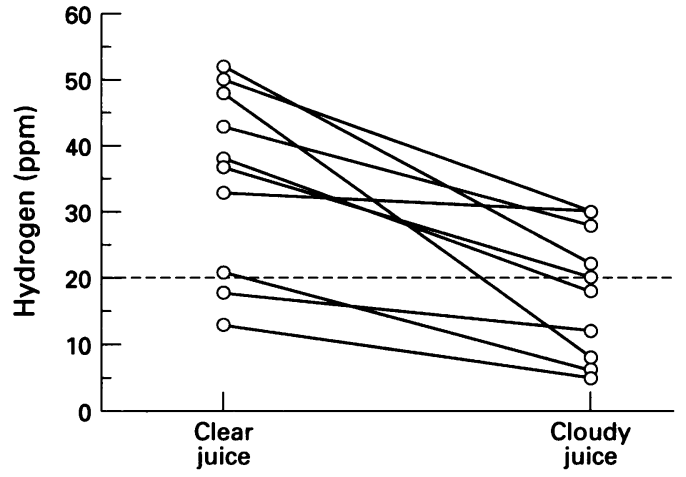

Figure 1 Individual peak breath hydrogen increases (Ppm) in 10 healthy children after ingestion of clear compared with cloudy apple juice; mean (SEM) clear juice 35 (4) and cloudy juice 18 (3) ppm. Interrupted line denotes upper limit of normal.

groups using the $\chi^{2}$ test. As in the trial period related effects could not be excluded beforehand, an analysis in conformity with Senn ${ }^{12}$ was chosen: a linear model with the diarrhoea score as dependent variable, with three factors as independent variables (patient with 12 levels, treatment with three levels, period with three levels), and with liquid intake $(\mathrm{ml} / \mathrm{kg}$ body weight) as covariable. This model was analysed using procedure GLM from the SAS package (SAS Institute Inc, Cary, North Carolina).

\section{Results}

BREATH TESTS

Judged by peak hydrogen concentrations $\geqslant 20$ ppm, eight out of 10 healthy children demonstrated carbohydrate malabsorption after the ingestion of clear apple juice as compared with five out of 10 after cloudy apple juice (not significant). Mean peak hydrogen increases,

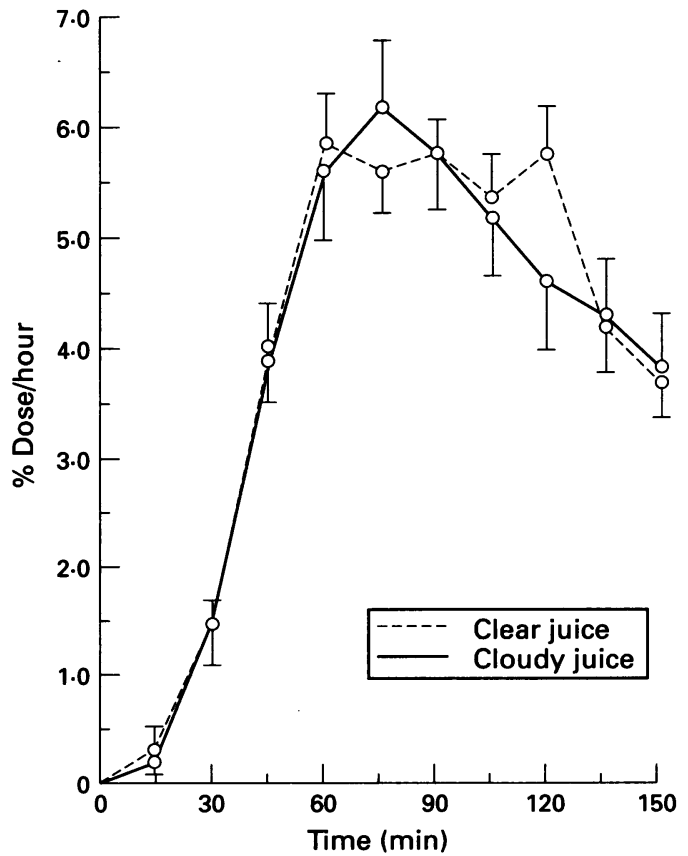

Figure 2 Gastric emptying rate in five healthy children after administration of $40 \mathrm{mg}$ of ${ }^{13} \mathrm{C}$-glycine. Mean (SEM) of ${ }^{13} \mathrm{CO}_{2}$ excretion, expressed as \% dose/hour, after ingestion of clear and cloudy apple juice. however, were significantly different (35 (4) and 18 (3) ppm, respectively; $p<0.001$ ) (fig 1 ). The results of the gastric emptying studies were normal in all children and did not differ between clear and cloudy apple juice at any moment, independent of the mode of expression: as a percentage of ${ }^{13} \mathrm{CO}_{2}$ recovery in breath (\% excretion/hour of the given ${ }^{13} \mathrm{C}$ dose) (fig 2); as half emptying time (clear juice 38 (5) $\mathrm{min}$, as compared with cloudy juice 35 (4) min; $p=0.54)$; or as gastric emptying coefficient $(3 \cdot 7(0 \cdot 1)$ and $3.9(0 \cdot 2)$, respectively; $\mathrm{p}=0.35)$.

\section{CLINICAL TRIAL}

Mean basal fluid intake (excluding dairy products) in the 12 children was 24 (3) $\mathrm{mg} / \mathrm{kg}$ body weight/day, range $10-49 \mathrm{ml} / \mathrm{kg} /$ day. In the extra clear fluid intervention period, all children had succeeded in drinking at least $50 \%(59-273 \%)$ extra, fluid consumption being calculated as 48 (6) $\mathrm{ml} / \mathrm{kg} /$ day (fig 3). Surprisingly, although not instructed to do so, the total fluid intakes with both the clear (45 (4) $\mathrm{ml} / \mathrm{kg} /$ day) and cloudy apple juice intervention periods (42 (3) $\mathrm{ml} / \mathrm{kg} /$ day) were higher as well (fig 3). During the weekly home visits no significant changes in other components of the diets (meals, dairy products) had become apparent. The diarrhoea scores for the four different periods varied greatly between patients, with mean scores of $3.5(1.3), 4.2(1.6), 5.2$ $(1 \cdot 6)$, and $14 \cdot 2(4 \cdot 3)$ for basal, extra clear fluids, cloudy juice, and clear juice, respectively. The individual results for fluid intake and diarrhoea score are presented in table 1.

Statistical analysis did not reveal any significant period effect for diarrhoea score $(p=0.82)$; furthermore, no relation with fluid intake as the covariable could be demonstrated $(p=0 \cdot 85)$. There was, however, a significant effect related to treatment $(p=0 \cdot 014)$. Further evaluation of the treatment factor by means of estimates of contrasts between treatments showed that there was no significant difference between the effects of cloudy apple juice and extra fluids, while the differences between the effects of clear and cloudy apple juice as well as

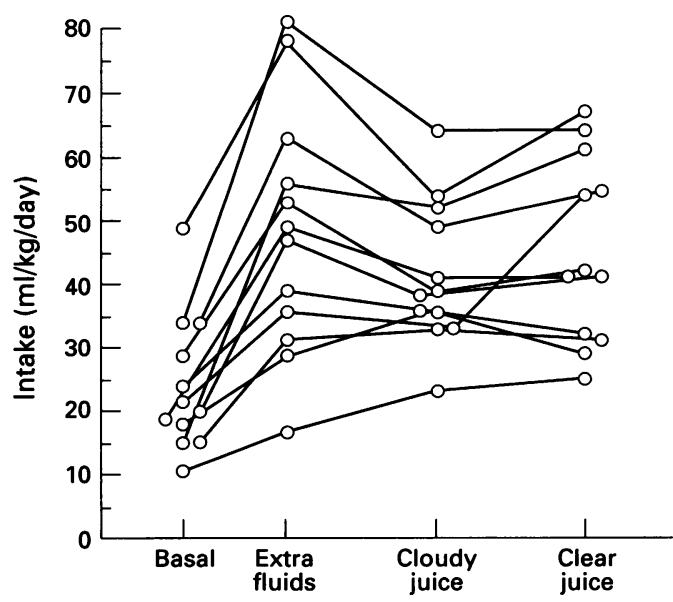

Figure 3 Individual consumptions of clear fluids during basal and three intervention periods in 12 children previously diagnosed as having CNSD. 
Table 1 Results of intervention studies: five day diarrhoea scores

\begin{tabular}{lcccc}
\hline Patient No & Basal period & Extra clear fluids & Cloudy apple juice & Clear apple juice \\
\hline 1 & 0 & 3 & 0 & 8 \\
2 & 1 & 0 & 0 & 11 \\
3 & 8 & 15 & 16 & 26 \\
4 & 3 & 2 & 15 & 19 \\
5 & 12 & 13 & 4 & 49 \\
6 & 0 & 2 & 4 & 28 \\
7 & 11 & 4 & 3 & 3 \\
8 & 3 & 0 & 0 & 0 \\
9 & 1 & 0 & 0 & 19 \\
10 & 0 & 0 & 4 & 2 \\
11 & 0 & 10 & $5 \cdot 2(1 \cdot 6)$ & $14 \cdot 2(4 \cdot 3)$ \\
12 & 3 & $4 \cdot 2(1 \cdot 6)$ & & \\
Mean (SEM) & $3 \cdot 5(1 \cdot 3)$ & & & \\
\hline
\end{tabular}

those between the effects of clear apple juice and extra fluids were highly significant (table 2).

\begin{abstract}
Discussion
CNSD is an important source of parental anxiety. It is the most common cause of chronic diarrhoea without failure to thrive in early childhood. ${ }^{11}$ Surprisingly, research in this field has been rather scarce. Fenton et al found a disordered small intestinal motility in CNSD patients: contrary to control children, they exhibited an uninterrupted fasting motility pattern when a carbohydrate solution was instilled into the stomach. ${ }^{13}$ Cohen et al demonstrated that many of these children have low fat intakes, and that their defecation patterns improved when dietary fat was increased to normal or supranormal levels; this could be explained by the effects of fats and carbohydrates on intestinal motility. ${ }^{6}$ Furthermore, children with CNSD often have increased fluid consumption, which also may contribute to the perseverance of diarrhoea. ${ }^{5} \mathrm{It}$ was demonstrated that especially apple juice consumption is related to CNSD. ${ }^{12}$ It will be clear, however, that dietary manipulation of one macronutrient will influence the ingestion of the other macronutrients as well. Moreover, many dietary peculiarities will be secondary to the chronic diarrhoea and based on ill grounded advice and fears.
\end{abstract}

The study presented here was prompted by our clinical impression that cloudy apple juice, which is sold in health food stores as a more natural alternative, was less likely to cause diarrhoea than the normal clear apple juices. We sought to investigate the role of apple juice and fluid consumption in children who had previously had CNSD with as little disruption of their normal diet as possible. Because of the possible influence of carbohydrate composition on gastric motility, we used a noninvasive technique ${ }^{79}$ in healthy children to determine gastric emptying and breath hydrogen excretion after consumption of the two juices. We were able to demonstrate that

Table 2 Multivariate analysis in a linear model with diarrhoea score as dependent variable, three interventions as independent variables, and liquid intake as covariable

\begin{tabular}{lccc}
\hline Interventions & Estimate of contrast & 95\% Confidence interval & $p$ Value \\
\hline Cloudy apple juice $v$ extra clear fluid & 1.4 & -6.5 to 9.3 & 0.73 \\
Clear $v$ cloudy apple juice & $8 \cdot 8$ & 1.7 to 15.9 & 0.02 \\
Clear apple juice $v$ extra clear fluid & 10.2 & 3.3 to 17.1 & 0.01
\end{tabular}

cloudy apple juice caused less carbohydrate malabsorption without slowing down gastric emptying. This lack of effect on gastric emptying is in agreement with studies in adults showing that low concentrations of soluble fibres have no influence on gastrointestinal motility. 1415

In the field study, children with a previously established diagnosis of CNSD and with normal total fluid consumption did not respond with diarrhoea on increased clear fluid intakes as the sole change in dietary habits. Our findings contrast with those of Greene and Ghishan, but their study was based on a retrospective inquiry on children referred for symptoms of CNSD before any dietary advice was given. ${ }^{5}$ Supposedly the diets of their patients were relatively low in fat which decreases intestinal transit time. ${ }^{6}$ Moreover, the total fluid intake as used in their study cannot be compared with our values as for practical reasons we only focused on the clear fluids in between meals, neglecting dairy products. Nevertheless, within 'normal' limits fluid intake itself does not seem to be a critical factor in CNSD.

By contrast, replacing clear fluids (other than apple juice) with clear apple juice led to a significant increase of the diarrhoea score, indicating a direct effect of apple juice on gastrointestinal function. This effect, which itself could be anticipated in view of previous findings, ${ }^{12}$ has never before been demonstrated in a prospective study. It has to be kept in mind that these children were former CNSD patients with no symptoms for at least three months, while even without measures CNSD tends to improve with time. Despite the fact that fluid consumption was not especially stimulated during the apple juice periods, the children increased their fluid consumptions to the levels obtained in the extra clear fluid period, rendering the three intervention periods identical in terms of fluid consumption. This may relate to the fact that young children, Dutch children at least, highly appreciate the taste of apple juice.

Interestingly, no rise in diarrhoea score was noted when normal, clear apple juice was replaced by unprocessed, cloudy apple juice. The main difference between the two juices is the higher amount of cell wall fibres in cloudy apple juice. In the industrial processing of clear apple juice, the fibre content is diminished by enzymatic breakdown. It is well known that the amount and physical quality of fibres in apples influence their physiological and metabolic effects on the human body. ${ }^{1617}$ The raw material for apple juice is apple pulp. The fibres found in apple pulp are mainly pectin and pectin-like substances, and other cell wall polysaccharides such as cellulose and hemicelluloses are present in low concentrations. ${ }^{18}$ For the production of clear apple juice the apple pulp is enzyme treated resulting in greater produce and removal of cloudiness. The enzyme mixture mostly applied contains polygalacturonidase and pectate lyase, both of which are involved in the degradation of pectin, and hemicellulases. ${ }^{1819}$ The polysaccharides thus 
are degraded to monosaccharides and oligosaccharides, mainly galacturonic acid. Both pectin and hemicellulose are completely degraded by the intestinal flora. As with other carbohydrates, the main groups of bacteria involved in degradation are Clostridium spp and Bacteroides spp. Fermentation by these bacteria results in the formation of short chain fatty acids and gases including hydrogen. ${ }^{20}$ As both the small bowel transit and the fermentation of monosaccharides and oligosaccharides proceed at much faster rates than those of polysaccharides, it may be anticipated that the ingestion of cloudy apple juice will result in a slower, but prolonged, increase in breath hydrogen. Consequently, although malabsorption of fructose may play a part in apple juice induced diarrhoea, other carbohydrates seem to be of equal importance. They do not influence stool consistency when consumed as polysaccharides, but contribute to both hydrogen production and diarrhoea when enzymatically degraded to undigestible monosaccharides and oligosaccharides.

Unfortunately, the reliable determination of the amounts of undigestible carbohydrates in the two juices poses major technical problems. Due to their low concentrations, the polysaccharides in apple juice are difficult to quantitate, and for the assessment of the undigestible monosaccharides and oligosaccharides there is no standardised quantitative method available. Moreover, no single technique is capable of the simultaneous assessment of oligosaccharides and polysaccharides. For the moment, therefore, we have to rely on the theoretical considerations mentioned above.

In conclusion, both hydrogen production and clinical effects differ depending on the type of apple juice investigated, 'clear' or 'cloudy'. We speculate that the industrial processing of apples by means of enzymatic degradation, leading to increased availability of nonabsorbable monosaccharides and oligosaccharides, would explain for the greater part why apple juice consumption may cause diarrhoea in young children.
We would like to thank Th de Boo, Department of Medical Statistics, Katholieke Universiteit Nijmegen, for methodological advice and statistical evaluation of the results.

This study was supported by a grant from the Peribosch foundation.

1 Hyams JS, Leichtner AM. Apple juice: an unappreciated cause of chronic diarrhea. Am $\mathcal{f}$ Dis Child 1985; 139: 503-5.

2 Kneepkens CMF, Douwes AC, Jakobs C. Apple juice, fructose, and chronic nonspecific diarrhoea. Eur $\mathcal{F}$ Pediatr 1989; 148: 571-3.

3 Lifshitz F, Ament ME, Kleinman RE, et al. Role of juice carbohydrate malabsorption in chronic nonspecific carbohydrate malabsorption in chronic no

4 Hoekstra JH, Van Kempen AAMW, Kneepkens CMF. Apple juice malabsorption: fructose or sorbitol? $\mathcal{f}$ Pediatr Apple juice malabsorption: fructose

5 Greene HL, Ghishan FK. Excessive fluid intake as a cause of chronic diarrhea in young children. $\mathcal{F}$ Pediatr 1983; 102: 836-40.

6 Cohen SA, Hendricks KM, Mathis RK, Laramee S, Walker WA. Chronic nonspecific diarrhea: dietary relationships. Pediatrics 1979; 64: 402-7.

7 Maes BD, Ghoos YF, Geypens BJ, et al. The combined carbon-13-glycine/carbon-14-octanoic acid breath test to monitor gastric emptying rates of liquids and solids. $f$ Nucl Med 1994; 35: 824-31.

8 Van der Klei- van Moorsel JM, Douwes AC, van Oeveren JP. New principle for estimation of hydrogen in expired air. Eur f Pediatr 1984; 141: 221-4.

9 Ghoos YF, Geypens BJ, Maes BD, Hiele MI, Vantrappen G, Rutgeers PJ. Breath tests in gastric emptying and transit studies: technical aspects of ${ }^{13} \mathrm{Ca}_{2}$-breath tests. In: Janssens , ed. Progress in understanding and management of gastro

10 Haycock GB, Schwartz GJ, Wisotsky DH. Geometrical method for measuring body surface area: a height-weight method for measuring body surface area: a height-weight 1978; 93: 62-6.

11 Davidson $M$, Wasserman $R$. The irritable colon of childhood (chronic nonspecific diarrhea syndrome). $\mathcal{f}$ Pediatr 1966; 69: 1027-38

2 Senn S. Cross-over trials in clinical research. Chichester: John Wiley and Sons, 1993: 135-8.

13 Fenton TR, Harries JP, Milla PJ. Disordered small intestinal motility: a rational basis for toddler's diarrhoea. Gut 1983; 24: 897-903

14 Spiller GA, Chernoff MC, Hill RA, Gates JE, Nassar JJ, Shipley EA. Effect of purified cellulose, pectin, and a lowresidue diet on fecal volatile fatty acids, transit time, and fecal weight in humans. Am f Clin Nutr 1980; 33: 754-9.

15 Tadesse K. The effect of dietary fibre isolates on gastric secretion, acidity and emptying. Br $f$ Nutr 1986; 55: 507-13.

16 Haber GB, Heaton KW, Murphy D. Depletion and disruption of dietary fibre. Effects on satiety, plasma-glucose, and serum-insulin. Lancet 1977; ii: 679-82.

17 Anderson JW. Physiological and metabolic effects of dietary fibre. Fed Proc 1985; 44: 2902-6.

18 Pilnik W. Enzymes in the beverage industry (fruit juices, nectar, wine, spirits and beer). In: Dupuy $\mathrm{P}$, ed. Use of enzymes in food technology. Paris: Lavoisier, 1982: 425-50.

19 Voragen AGJ, Geerst F, Pilnik W. Hemi-cellulases in enzymatic fruit processing. In: Dupuy $\mathrm{P}$, ed. Use of enzymes in food technology. Paris: Lavoisier, 1982: 497-502.

20 Adiotomre J, Eastwood MA, Edwards CA, Brydon WG. Dietary fiber: in vitro methods that anticipate nutrition and metabolic activities in humans. Am $\mathcal{f}$ Clin Nutr 1990; 52: 128-34. 